\title{
Paraplegia prevention by oral pretreatment with memantine in a rabbit model
}

Nirmal Panthee, MBBS, ${ }^{\text {a }}$ Minoru Ono, MD, PhD, ${ }^{\text {a }}$ Tetsuro Morota, MD, PhD, ${ }^{\text {a }}$ Tsuruhito Tanaka, MD, ${ }^{a}$ Yoshifumi Itoda, $\mathrm{MD}, \mathrm{PhD},{ }^{a}$ Masako Ikemura, $\mathrm{MD}, \mathrm{PhD},{ }^{\mathrm{b}}$ Takehito Yamamoto, $\mathrm{PhD},{ }^{c}$ Hiroshi Suzuki, PhD, ${ }^{\mathrm{c}}$ Aya Saito, $\mathrm{MD}, \mathrm{PhD},{ }^{\mathrm{a}}$ and Noboru Motomura, $\mathrm{MD}, \mathrm{PhD}^{\mathrm{a}}$

Objective: To evaluate the role of memantine ( $N$-methyl-D-aspartate receptor antagonist) pretreatment for the prevention of spinal cord ischemia after infrarenal aortic clamping in a rabbit model.

Methods: Thirty New Zealand White rabbits were divided into 5 different groups of 6 rabbits. Groups 60-7 and 60-5 received oral memantine $60 \mathrm{mg}$ once a day for 7 and 5 days, respectively, and groups 30-5 and 30-3 received oral memantine $30 \mathrm{mg}$ once a day for 5 and 3 days, respectively, all before surgery. Group C (control) received normal feeds without memantine. A paraplegic model was created by clamping both the aorta and the inferior vena cava infrarenally and just proximal to their bifurcations for 45 minutes. The modified Tarlov score, motor evoked potential (MEP), serum memantine concentration, and histopathology of the spinal cord were evaluated.

Results: The mean modified Tarlov scores were $4.2 \pm 1.3,4.3 \pm 1.0,4.2 \pm 1.3,4.3 \pm 1.2$, and $0.8 \pm 1.6$ in groups 60-7, 60-5, 30-5, 30-3, and C, respectively at 6, 24, 48, and 72 hours $(P<.009$ for individual groups vs control). Percentage amplitude loss of MEP by the end of surgery was $29.5 \% \pm 46.3 \%, 11.9 \% \pm 28.0 \%$, $30.0 \% \pm 46.8 \%, 16.7 \% \pm 40.8 \%$, and $81.8 \% \pm 40.3 \%$ for the 5 groups, respectively $(P=.049)$. After declamping, MEP reappeared in $83 \%, 100 \%, 83 \%, 83 \%$, and $33 \%$ of cases in the 5 groups, respectively $(P=.073)$. The serum memantine level was similar in the 4 memantine groups. Spinal cords were normal in most of the rabbits in groups 60-7, 60-5, 30-5, and 30-3, but severely ischemic in most of the rabbits in group $\mathrm{C}(P=.041)$.

Conclusions: Oral memantine pretreatment is protective against spinal cord ischemia, and can be an additional strategy for the prevention of paraplegia during thoracoabdominal aortic surgeries. (J Thorac Cardiovasc Surg 2014;148:1732-8)

Spinal cord injury is a devastating complication after thoracoabdominal aortic aneurysm (TAAA) repair. Its incidence has been reported to range from $2 \%$ to $31 \%$ depending on the series. ${ }^{1-9}$ This seemingly large difference between series is due to the varying proportion of high-risk patients and the use of different surgical adjuncts for spinal protection, and because some studies did not have a large enough number of cases. Paraplegia after TAAA repair carries a huge burden of physical disability and is associated with decreased survival.

Impaired cord perfusion during aortic clamping, intraoperative and perioperative hypotension, failure to reestablish

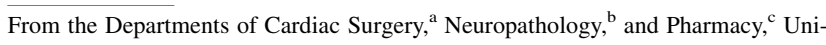
versity of Tokyo, Hongo Bunkyo-ku, Tokyo, Japan.

Disclosures: H. Suzuki received some grant support from Daiichi Sankyo Co. Ltd. for measuring serum levels of memantine. T. Yamamoto receives lecture fees from Astellas Pharma Inc, Novartis Pharma, and Chugai Pharmaceutical Co. Ltd. All other authors have nothing to disclose with regard to commercial support.

Received for publication March 21, 2014; revisions received April 22, 2014; accepted for publication April 24, 2014; available ahead of print June 6, 2014.

Address for reprints: Minoru Ono, MD, PhD, Department of Cardiac Surgery, University of Tokyo, 7-3-1 Hongo, Bunkyo-ku, Tokyo, 113-8655 Japan (E-mail: ono-tho@h.u-tokyo.ac.jp).

$0022-5223 / \$ 36.00$

Copyright (๑) 2014 by The American Association for Thoracic Surgery

http://dx.doi.org/10.1016/j.jtcvs.2014.04.043 cord flow on completion of surgery, and reperfusion injury all contribute to spinal cord injury. ${ }^{10}$ A multimodality approach with several surgical adjuncts has long been adopted to help prevent paraplegia; which includes maintenance of high normal blood pressures, ${ }^{7}$ moderate to profound hypothermia, ${ }^{7,11}$ topical spinal cord hypothermia, ${ }^{7}$ drainage of cerebrospinal fluid (CSF), ${ }^{12}$ left heart bypass, ${ }^{13}$ and reattachment of segmental intercostal or lumbar arteries. ${ }^{1,2,4}$ The role of pharmacologic protection has also been considered in most adjuncts, including steroids, ${ }^{7}$ naloxone, ${ }^{10}$ and free radical scavengers, ${ }^{14}$ among many others.

$N$-methyl-D-aspartate (NMDA) receptors have been shown to have an important role in mediating calciummediated injury in neuronal tissue after a variety of insults, including ischemic ${ }^{15}$ (Figure 1). NMDA receptors are composed of NR1, NR2, NR3A or NR3B subunits, and activation of these receptors requires dual agonists, glutamate and glycine. ${ }^{16,17}$ During ischemia, glutamate and glycine are coreleased by reverse operation of Na-dependent transporters, thereby leading to subsequent activation of NMDA receptors ${ }^{18}$ with subsequent injury of neuronal tissue. Ehrlich and colleagues ${ }^{19}$ showed the role of intravenous and intraarterial memantine, a noncompetitive antagonist of NMDA receptors, for the prevention of spinal cord ischemia in a rabbit model. We evaluated the neuroprotective role of 

Abbreviations and Acronyms
AMPA $=\alpha$-amino-3-hydroxy-5-methyl-4- isoxazole proprionate
$\mathrm{CSF}=$ cerebrospinal fluid
IVC = inferior vena cava
MEP $=$ motor evoked potential
NMDA $=N$-methyl-D-aspartate
TAAA $=$ thoracoabdominal aortic aneurysm

oral memantine pretreatment after infrarenal aortic clamping in a rabbit model.

\section{METHODS}

Thirty New Zealand White rabbits weighing $3.2 \mathrm{~kg}$ (range, 2.8-3.4 kg) were used for the experiment. Rabbits were acquired from a rabbit farm about 10 days before surgery and were allowed to adapt to the new environment in our animal laboratory, with full access to food and water and free movement inside the cage. All animals received full humane care in compliance with the Guide for the Care and Use of Laboratory Animals established by the United States National Institutes of Health and the study was approved by the Animal Ethical Committee at the University of Tokyo (approval ID, P12-86). Memantine was purchased from Daiichi Sankyo Co. Ltd (Tokyo, Japan). The final food was prepared by Oriental Yeast Co. Ltd (Tokyo, Japan) to achieve a memantine concentration of $0.048 \%(\mathrm{w} / \mathrm{w})$. Rabbits were then divided into 5 groups of 6. Groups 60-7 and 60-5 received oral memantine $60 \mathrm{mg}$ once a day for 7 and 5 days, respectively, before surgery. Groups 30-5 and 30-3 received oral memantine $30 \mathrm{mg}$ once a day for 5 and 3 days, respectively, before surgery. Group C (control) received normal feeds without memantine.

All rabbits were anesthetized with an initial dose of intramuscular ketamine $100 \mathrm{mg}$ and xylazine $20 \mathrm{mg}$ without endotracheal intubation. A repeat dose (ketamine $100 \mathrm{mg}$ and xylazine $10 \mathrm{mg}$ ) was given intramuscularly 45 minutes after the initial dose. A maintenance dose of ketamine was given as a continuous intravenous infusion at $5 \mu \mathrm{g} / \mathrm{kg} / \mathrm{min}$. Oxygen was administered via facemask at $2 \mathrm{~L} / \mathrm{min}$. Arterial and venous access was obtained using a 24-gauge cannula from the central auricular artery and marginal auricular vein, respectively. Ringer lactate solution $(8 \mathrm{~mL} / \mathrm{kg} / \mathrm{h})$ was infused as maintenance fluid intraoperatively. The core body temperature was measured using a rectal probe. Temperature was maintained as normal as possible by using a heating pad, halogen light, and an infusion of lukewarm maintenance fluid.

A midline laparotomy incision (10 cm long) was made. The bowels were reflected toward the right, and the abdominal aorta and inferior vena cava (IVC) were exposed by incising the retroperitoneum. The aorta and IVC were taped and bulldog clamps were applied to both infrarenally and just proximal to their bifurcations. Clamping was continued for $45 \mathrm{mi}-$ nutes. At the end of 45 minutes, both the aorta and IVC were declamped and the abdomen was closed in 2 layers. Bolus heparin (100 units/kg) was injected intravenously 3 minutes before aortic clamping. Activated clotting time was not measured and heparin was not reversed at the end of the procedure. The rabbits were observed for about 6 hours in the operating room, and then transferred to the cage. They were allowed free access to food, water, and mobility inside the cage.

Paraplegia was evaluated by modified Tarlov score $(0$, no movement of lower limbs; 1 , slight movement of lower limbs; 2 , sits with support; 3 , sits alone; 4, weak hop; 5, normal hop) at 6, 24, 48, and 72 hours. At 72 hours, the rabbits were killed by intracardiac injection of 10 mequiv $\mathrm{KCl}$. The lumbar segments of the spinal cords were harvested and stored in $10 \%$ formalin solution for 2 to 3 weeks before histopathologic examination by a neuropathologist who was blinded to the treatment model. Sections were cut $3-\mu \mathrm{m}$ thick and stained with hematoxylin and eosin. In each section, we looked for normal neurons with a polygonal cell body with a cytoplasmic extension, centrally located round the nuclei with a prominent nucleolus; degenerated neurons (red neurons, ghost neurons, chromatolytic neurons, and neurons with vacuolization); and neuronal loss. Grading of the severity of necrosis was done by dividing the gray matter, excluding the posteriormost part containing sensory neurons, into 4 quadrants: right anterior, left anterior, right posterior, and left posterior. Histopathology was reported as normal if none of the 4 quadrants showed evidence of degenerated neurons or neuronal loss. Histopathology was reported as mild, moderate, or severe ischemia if only 1 quadrant, 2 quadrants, and 3 or all 4 quadrants, respectively, showed evidence of degenerated neurons or neuronal loss.

Motor evoked potentials (MEP) were monitored using a multiple electrical transcranial stimulator (Neuropack MEB-9400, Nihon Kohden, Tokyo, Japan). Stimuli consisting of a train of 5 pulses were applied to the skull with the anode placed at the frontal midline and the cathode at the central midline position. Compound action potentials were recorded from bilateral tibialis anterior by using needle electrodes. MEPs were recorded at baseline, before clamping, clamping 0 minutes, then every 2 minutes until 10 minutes, then every 5 minutes until 45 minutes, at declamping, then every 2 minutes until 5 minutes, every 5 minutes until 20 minutes, followed by every 10 minutes until 1 hour after declamping. The amplitude of the MEP, time to flat, and time to reappearance were analyzed. Flat MEP was defined as the loss of spike bilaterally after clamping. Reappearance of MEP was defined as any MEP waveform that was not flat (unilateral or bilateral) after the release of the clamp.

At the end of surgery, $5 \mathrm{~mL}$ of blood was centrifuged at $3000 \mathrm{rpm}$ for 10 minutes to obtain serum for measurement of the memantine concentration. Serum was stored at $-80^{\circ} \mathrm{C}$ for 2 to 3 weeks before the final analysis. Serum concentration was measured by validated liquid chromatographytandem mass spectrometry using 4-hydroxychalcone as the internal standard. The concentrations were expressed as $\mathrm{ng} / \mathrm{mL}$ of memantine free base.

\section{Statistical Analysis}

Statistical analysis was done using SPSS version 20 (SPSS Inc, Chicago, Ill). Data were expressed using the mean \pm standard deviation, median, range, and percentage wherever appropriate. The Mann-Whitney $U$ test, analysis of variance, and $\chi^{2}$ test were used depending on the variables.

\section{RESULTS}

\section{Baseline and Intraoperative Characteristics}

The baseline and intraoperative characteristics were similar for all 5 groups (Table 1).

\section{Evaluation of Paraplegia}

Paraplegia was evaluated clinically at $6,24,48$, and 72 hours using a modified Tarlov score. Mean modified Tarlov scores were $4.2 \pm 1.3,4.3 \pm 1.0,4.2 \pm 1.3,4.3 \pm 1.2$, and $0.8 \pm 1.6$ in groups $60-7,60-5,30-5,30-3$, and $\mathrm{C}$, respectively, at $6,24,48$, and 72 hours $(P<.009$ for individual groups vs control; $P=\mathrm{NS}$ among groups $60-7,60-5,30$ 5, and 30-3) (Figure 2). Tarlov score remained the same throughout the observation period and no cases of delayed onset paraplegia were seen.

\section{MEPs}

Baseline amplitudes of MEP were $16.8 \pm 8.1,17.9 \pm 6.5$, $18.5 \pm 4.7,16.6 \pm 6.3$, and $17.5 \pm 5.8 \mathrm{mV}$ in groups $60-7$, $60-5,30-5,30-3$, and $\mathrm{C}$, respectively $(P=.981)$. Median 


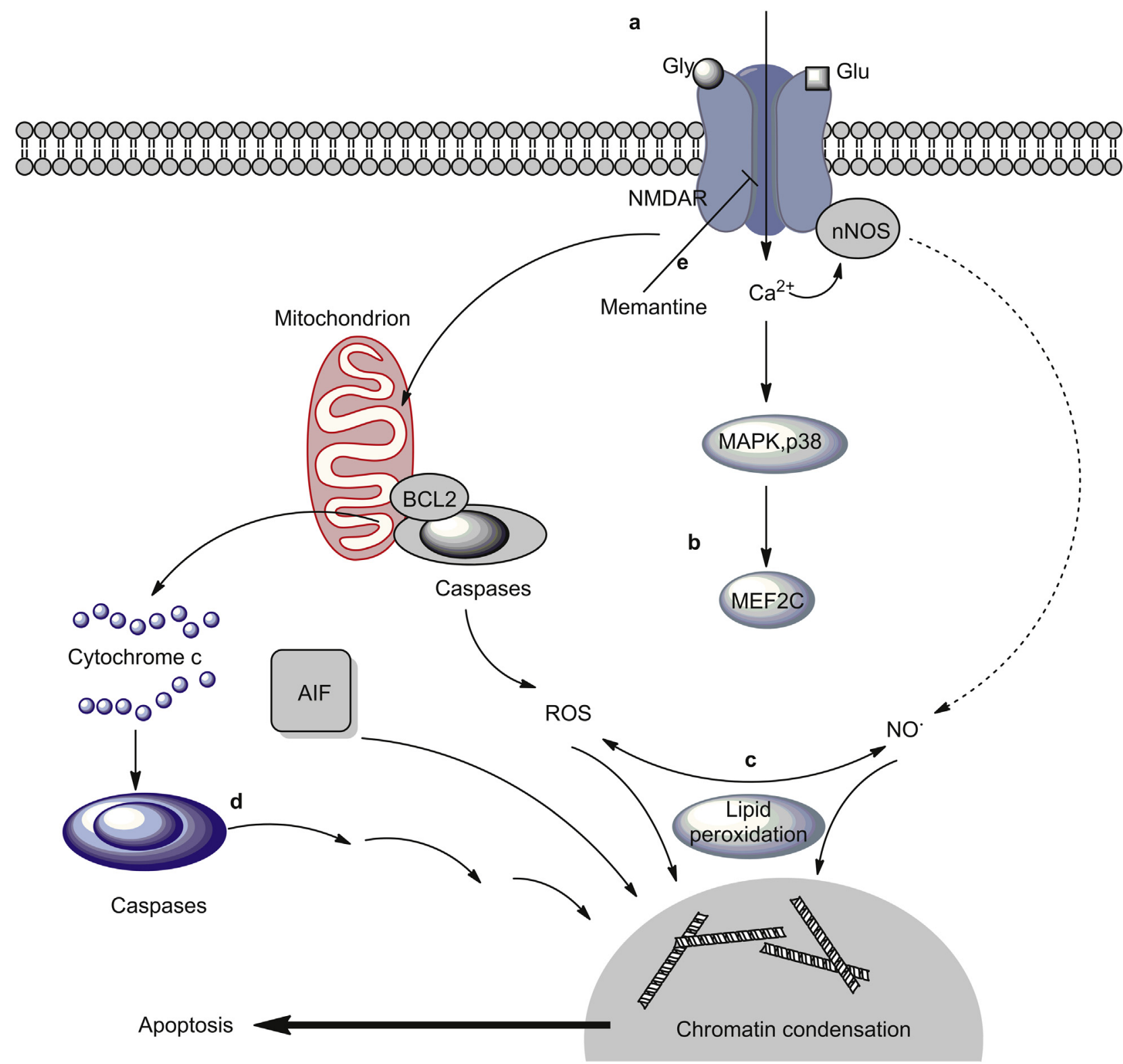

FIGURE 1. Apoptotic-like cell injury and death pathways triggered by excessive NMDAR activity and its prevention by memantine. The cascade includes: a, NMDAR hyperactivation; b, activation of the p38 MAPK-MEF2C (transcription factor) pathway (MEF2 is subsequently cleaved by caspases to form an endogenous dominant-interfering form that contributes to neuronal cell death); c, toxic effects of free radicals such as NO and ROS; d, activation of apoptosis-inducing enzymes including caspases and AIF; and e, blockade of NMDAR by memantine preventing $\mathrm{Ca}^{2+}$ influx into the neuronal cell with subsequent inhibition of steps a to d. Gly, Glycine; Glu, glutamate; NMDAR, N-methyl-D-aspartate receptor; nNOS, neuronal nitric oxide synthase; $M A P K$, mitogen-activated kinase; $B C L 2$, B-cell lymphoma 2; $M E F$, myocyte enhancer factor; $N O$, nitric oxide; ROS, reactive oxygen species; $A I F$, apoptosis-inducing factor. (Adapted from Lipton SA. Paradigm shift in neuroprotection by NMDA receptor blockade: memantine and beyond. Nat Rev Drug Discov. 2006;5:160-70; with permission from Nature Publishing Group).

time to flat MEP after clamping was $17,15,12,15$, and 5 minutes in groups $60-7,60-5,30-5,30-3$, and $\mathrm{C}$, respectively $(P=.048)$. After declamping, MEP reappeared in $83 \%, 100 \%, 83 \%, 83 \%$, and $33 \%$ of cases in groups 60 $7,60-5,30-5,30-3$, and $\mathrm{C}$, respectively $(P=.073)$. The mean values of percentage amplitude loss by the end of surgery from baseline values were $29.5 \% \pm 46.3 \%, 11.9 \% \pm$
$28.0 \%, 30.0 \% \pm 46.8 \%, 16.7 \% \pm 40.8 \%$, and $81.8 \% \pm$ $40.3 \%$ in groups $60-7,60-5,30-5,30-3$, and C, respectively $(P=.049)$. When MEP reappeared after declamping, the median (range) time to reappearance of the MEP was 5 (2-50), 2 (2-20), 2 (2-10), 2 (2-2), and 2 (2-2) minutes in groups $60-7,60-5,30-5,30-3$, and $\mathrm{C}$, respectively $(P=.183)$. 
TABLE 1. Baseline and intraoperative characteristics

\begin{tabular}{|c|c|c|c|c|c|c|}
\hline Variables & Group 60-7 & Group 60-5 & Group 30-5 & Group 30-3 & Group C & $P$ value \\
\hline \multicolumn{7}{|l|}{ Baseline characteristics } \\
\hline Body weight, mean $\pm \mathrm{SD}(\mathrm{kg})$ & $3.2 \pm 0.1$ & $3.2 \pm 0.2$ & $3.2 \pm 0.1$ & $3.1 \pm 0.2$ & $3.2 \pm 0.2$ & .617 \\
\hline Systolic BP, mean $\pm \mathrm{SD}(\mathrm{mm} \mathrm{Hg})$ & $86 \pm 11$ & $92 \pm 3$ & $87 \pm 5$ & $87 \pm 4$ & $92 \pm 9$ & .383 \\
\hline Heart rate, mean $\pm \mathrm{SD}(\mathrm{bpm})$ & $158 \pm 13$ & $159 \pm 11$ & $163 \pm 10$ & $170 \pm 29$ & $151 \pm 9$ & .372 \\
\hline Temperature, mean $\pm \mathrm{SD}\left({ }^{\circ} \mathrm{C}\right)$ & $39.2 \pm 0.3$ & $39.5 \pm 0.4$ & $39.3 \pm 0.5$ & $39.3 \pm 0.7$ & $39.2 \pm 0.3$ & .781 \\
\hline \multicolumn{7}{|l|}{ Intraoperative characteristics } \\
\hline Total operating time, mean $\pm \mathrm{SD}(\min )$ & $86 \pm 6$ & $88 \pm 4$ & $87 \pm 5$ & $89 \pm 7$ & $96 \pm 10$ & .132 \\
\hline Systolic BP, mean $\pm \mathrm{SD}(\mathrm{mm} \mathrm{Hg})$ & $67 \pm 17$ & $78 \pm 8$ & $78 \pm 5$ & $69 \pm 15$ & $74 \pm 9$ & .391 \\
\hline Heart rate, mean $\pm \mathrm{SD}(\mathrm{bpm})$ & $171 \pm 13$ & $168 \pm 11$ & $166 \pm 7$ & $169 \pm 27$ & $175 \pm 18$ & .877 \\
\hline Temperature, mean $\pm \mathrm{SD}\left({ }^{\circ} \mathrm{C}\right)$ & $37.7 \pm 0.4$ & $38.4 \pm 0.5$ & $38.1 \pm 0.7$ & $37.9 \pm 0.5$ & $38.4 \pm 0.4$ & .108 \\
\hline
\end{tabular}

$S D$, Standard deviation; $B P$, blood pressure.

\section{Serum Memantine Level}

The serum memantine level was $4.0 \pm 2.1,6.4 \pm 2.5,6.8$ \pm 2.4 , and $7.5 \pm 6.3 \mathrm{ng} / \mathrm{mL}$ in groups $60-7,60-5,30-5$, and 30-3, respectively $(P=.421$ ) (Figure $3, A)$. The serum levels ranged from 1.55 to $19.31 \mathrm{ng} / \mathrm{mL}$, which resulted in a Tarlov score of 5 (Figure 3, B).

\section{Histopathology}

The percentages of normal cords, cords with mild, moderate, and severe ischemia were $50 \%, 0 \%, 17 \%$, and $33 \%$; $67 \%, 0 \%, 17 \%$, and $17 \% ; 67 \%, 0 \%, 33 \%$, and $0 \% ; 50 \%$, $33 \%, 0 \%$, and $17 \%$; and $17 \%, 0 \%, 0 \%$, and $83 \%$ in groups 60-7, 60-5, 30-5, 30-3, and $\mathrm{C}$, respectively $(P=.041)$ (Figure 4, $A)$. Evaluation of the gray matter revealed normal neurons with polygonal cell body with a cytoplasmic extension, centrally located round nuclei with a prominent nucleolus in the memantine groups (Figure 4, $B$ ); the control group lacked these features and had degenerated neurons and neuronal loss (Figure 4, C).

\section{DISCUSSION}

Spinal cord injury after aortic surgery carries a significant risk of physical disability and increases the risk of mortality. ${ }^{3}$

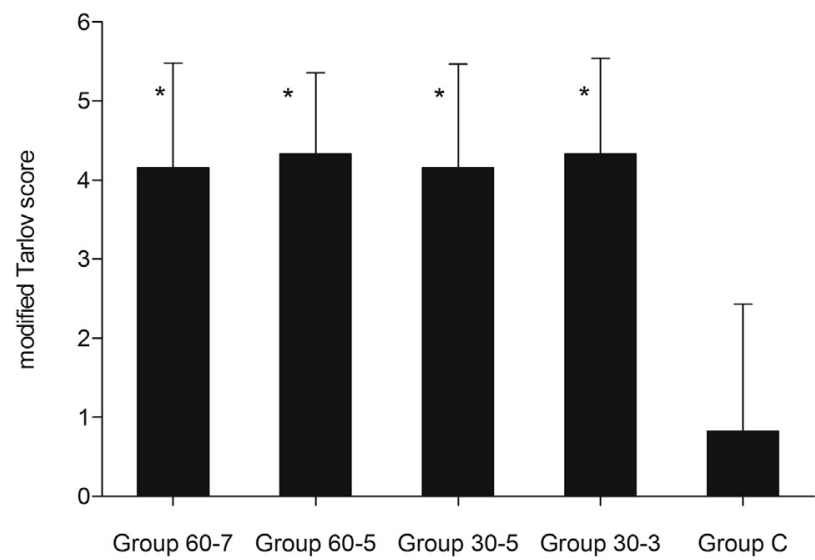

FIGURE 2. Modified Tarlov scores at $6,24,48$, and 72 hours. $* P<.009$ compared with group $C$; and $P$ is not significant among groups 60-7, 60-5, 30-5, and 30-3.
Total aortic crossclamp time, the extent of the aorta repaired, aortic rupture, patient age, proximal aortic aneurysm, and history of renal dysfunction are significant predictors of paraplegia. $^{3}$ The extent of the aneurysm has been consistently shown to be a major determinant of paraplegia after TAAA repair. ${ }^{3,4,7}$ Svensson and colleagues ${ }^{3}$ reported a $31 \%$ incidence of paraplegia after Crawford type II repairs compared with $6 \%$ after Crawford type I repairs; and the incidence increased further if accompanied by dissection. Dissection itself is a risk factor for paraplegia. ${ }^{10}$ Crossclamp time exceeding 30 minutes and emergency procedures also significantly increase the incidence of paraplegia. ${ }^{6}$

After so many years of basic and clinical research, thoracic vascular surgeons have been able to reduce the risk of paraplegia to outstandingly low levels, at least in expert hands ${ }^{8}$; however, total elimination of this complication is almost impossible because of the unavoidable interruption of spinal perfusion during the procedure. Recognition of predictors of paraplegia and implementation of various strategies including hypothermia with better understanding of Q10 for calculating the safe interval for interruption of spinal cord perfusion, ${ }^{11}$ Drainage of $\mathrm{CSF},{ }^{12}$ preoperative detection of the artery of Adamkiewicz by magnetic resonance angiography, ${ }^{20,21}$ reimplantation of critical intercostal and lumbar arteries, and the use of pharmacotherapeutic agents as adjuncts has contributed to better outcomes. In our institute, computed tomographyguided identification of the artery of Adamkiewicz by the Adamkiewicz protocol preoperatively and its reattachment during surgery; avoidance of opioids; use of mild hypothermia and partial cardiopulmonary bypass; MEP monitoring; CSF drainage, use of steroids, and naloxone in cases of noticeable MEP changes have given persistently good results for the prevention of paraplegia over the last several years. We insert a spinal drainage catheter in all patients; but institute CSF drainage at 15 $\mathrm{mL} / \mathrm{h}$ maintaining CSF pressure at $10 \mathrm{~cm} \mathrm{H}_{2} \mathrm{O}$ only if we notice changes in MEP.

NMDA receptors have an important role in mediating ischemic neuronal injury. ${ }^{15}$ Physiologic NMDA receptor 

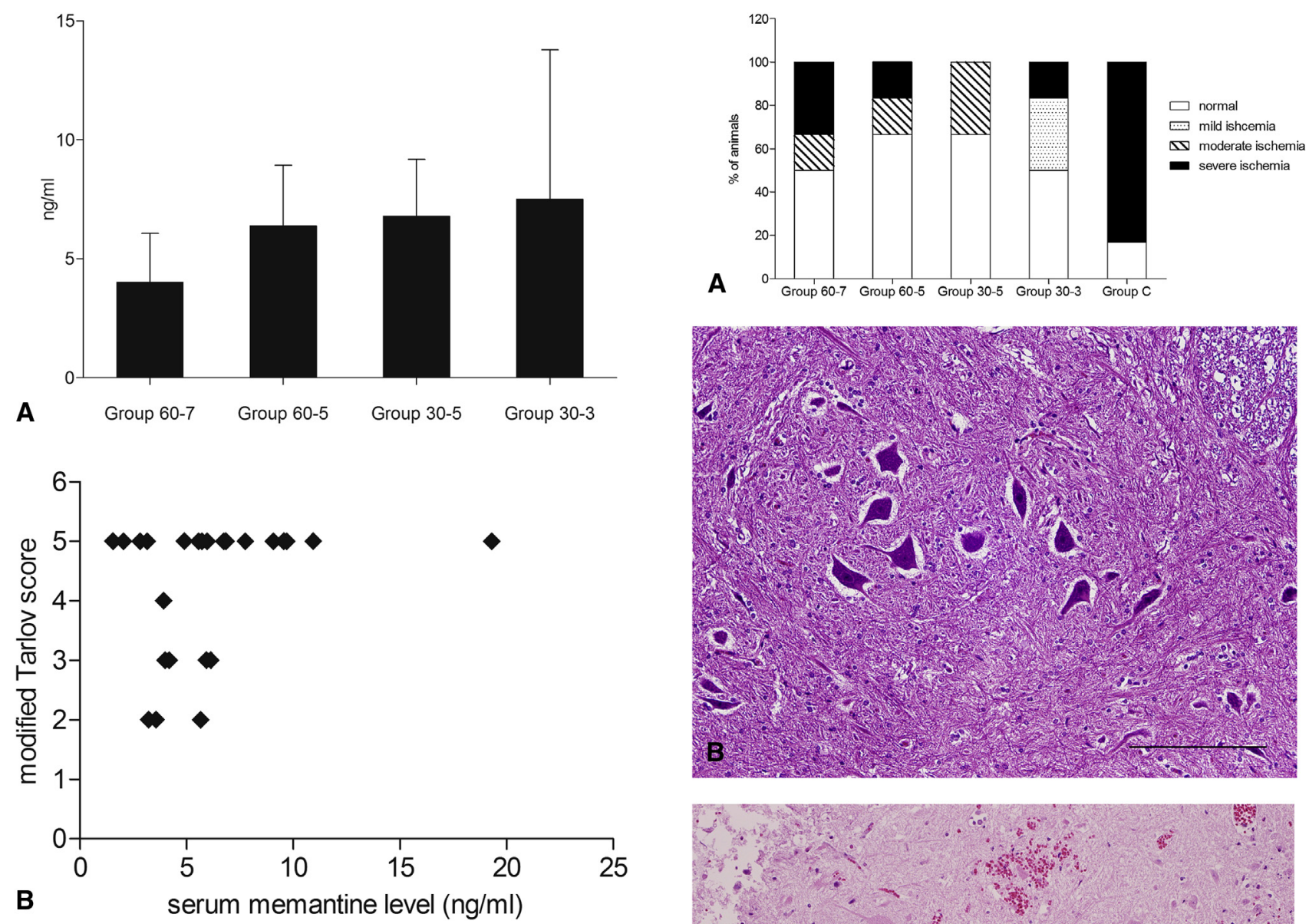

FIGURE 3. A, Serum level of memantine in groups 60-7, 60-5, 30-5, and 30-3. B, Scatter plot of serum memantine level versus modified Tarlov score.

activity is essential for normal neuronal function, ${ }^{22}$ and therefore must be preserved, even in the face of excessive pathologic activity in other areas of the central nervous system. However, excessive NMDA receptor activity is harmful and therefore should be prevented to maintain the integrity of the nervous system in the face of a variety of insults. ${ }^{15}$ Potential neuroprotective agents that manifest a high affinity for NMDA receptors block virtually all activity including physiologic signaling, and therefore probably have unacceptable clinical side effects. ${ }^{15}$ Memantine is unique in that it preferentially blocks excessive (pathologic) NMDA receptor activity without disrupting normal (physiologic) function. ${ }^{23}$ Memantine does this through its action as a low-affinity, but still highly selective, uncompetitive, open-channel blocker with a relatively rapid off rate from the channel. ${ }^{23}$ Moreover, the relatively fast off rate of memantine prevents the drug from accumulating in NMDA receptor-operated channels, so subsequent physiologic neurotransmission can proceed in a normal fashion. ${ }^{24,25}$ This fast off rate property contributes to the favorable profile of memantine in terms of its clinical tolerability
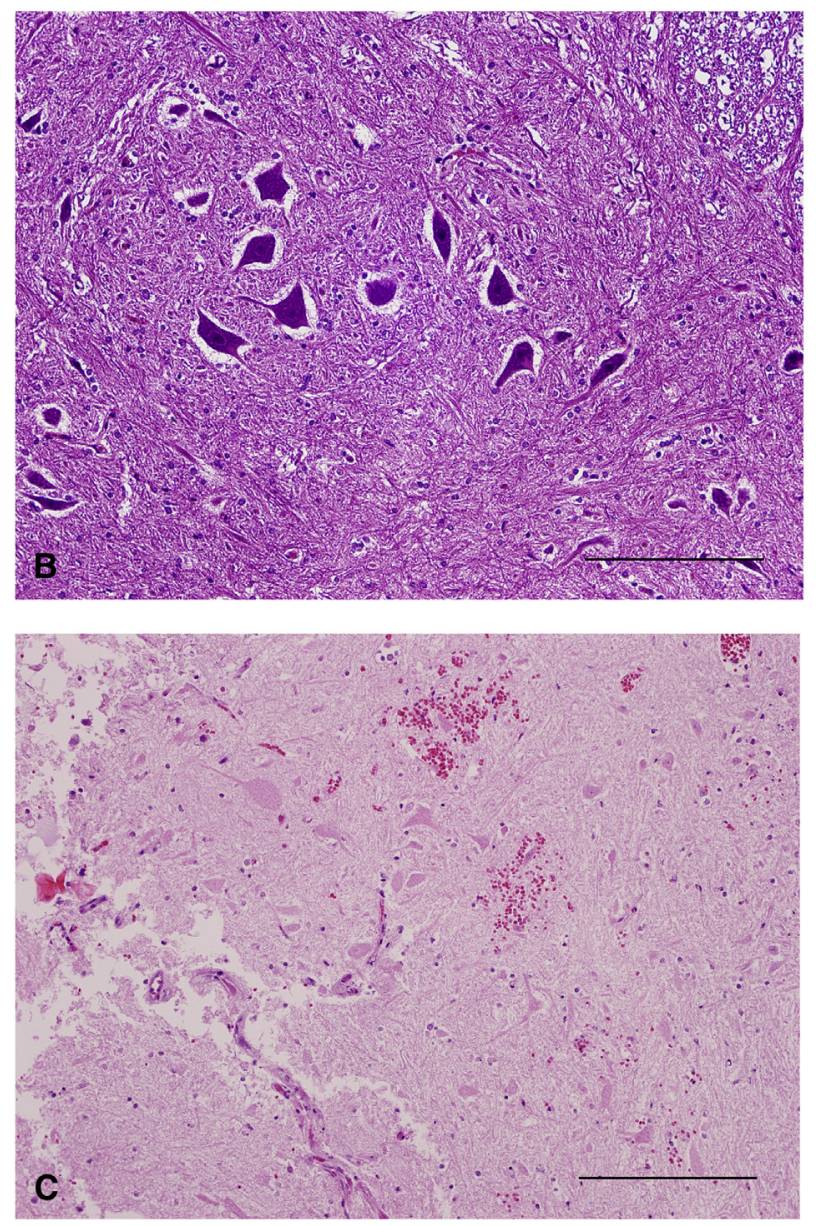

FIGURE 4. A, Distribution of normal cords, cords with mild, moderate, and severe ischemia in 5 different groups. B, Representative sample of a spinal cord (hematoxylin and eosin $[\mathrm{H} \& \mathrm{E}], \times 20$ ) in the memantine group showing normal neurons with polygonal cell body with a cytoplasmic extension, centrally located round the nuclei with a prominent nucleolus. $\mathrm{C}$, Representative sample of a spinal cord $(\mathrm{H} \& \mathrm{E} \times 20)$ in the control group showing degenerated neurons.

with a lower side effect profile compared with other NMDA receptor antagonists described before the discovery of memantine. ${ }^{26,27}$

Memantine has already been clinically approved for the treatment of Alzheimer dementia. Bioavailability after oral administration is approximately $100 \%$, and food does not alter its absorption. ${ }^{28}$ An oral dose of $20 \mathrm{mg}$ once a day as 

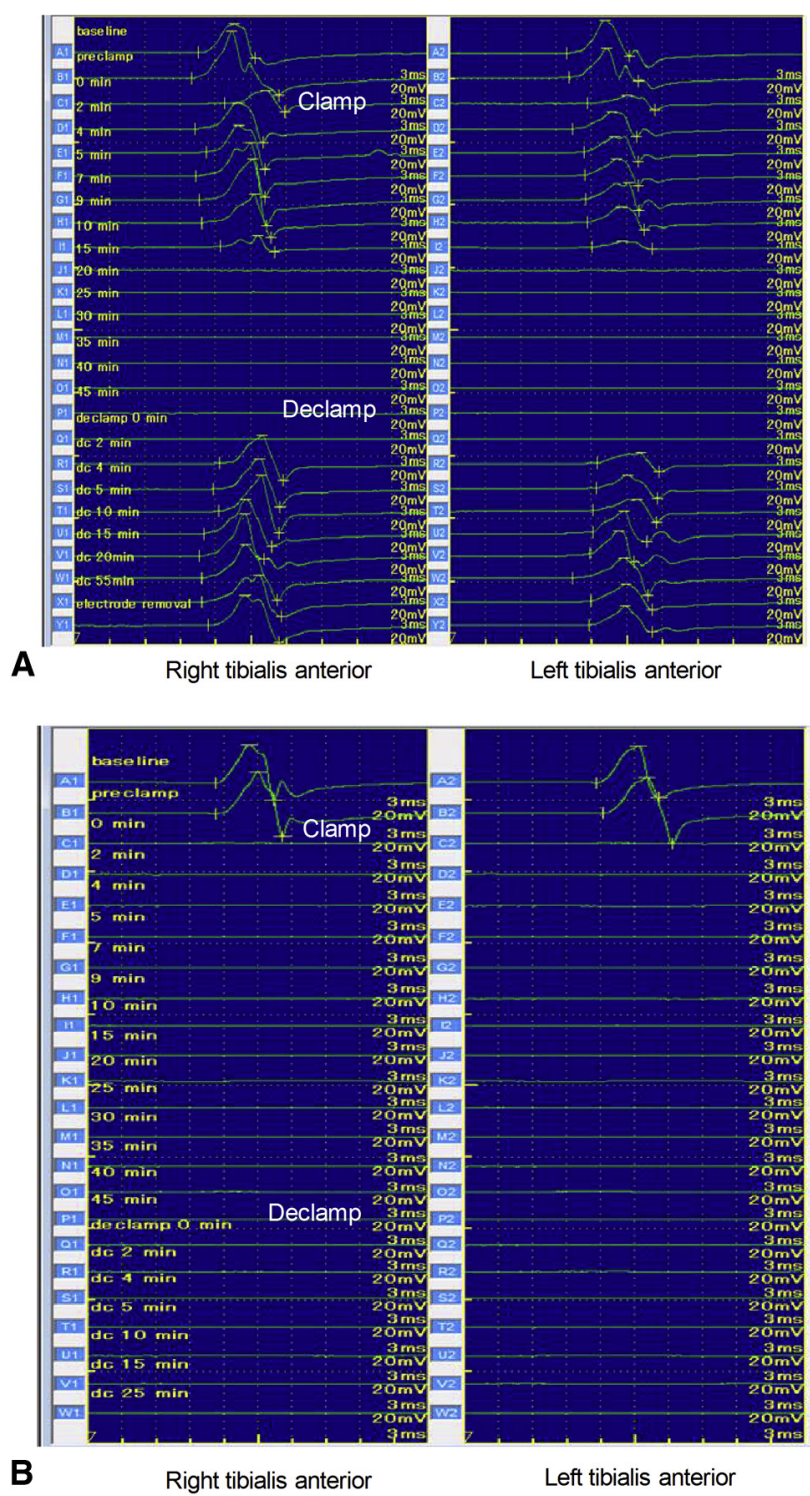

FIGURE 5. A, Typical MEP waveforms in the memantine group (note that after clamping, MEP persisted until 15 minutes, and after declamping, MEP reappeared in 2 minutes and persisted thereafter). B, Typical MEP waveforms in the control group (note that after clamping, MEP disappeared almost immediately, and after declamping, MEP did not reappear).

used clinically results in a wide range of serum concentrations from 72 to $182 \mathrm{ng} / \mathrm{mL}^{29,30}$; a single oral dose of 20 $\mathrm{mg}$ results in a serum concentration of $22.08 \mathrm{ng} / \mathrm{mL} .{ }^{31}$ Our medical regimen results in a serum concentration ranging from 1.55 to $19.31 \mathrm{ng} / \mathrm{mL}$, with the majority between 4 and $11 \mathrm{ng} / \mathrm{mL}$ (Figure 3, B). Although our treatment dosage (60 $\mathrm{mg}$ or $30 \mathrm{mg}$ once a day) was higher than the dosage used clinically, we achieved serum concentrations well below the level of toxicity. Although the serum memantine level in the 4 treatment groups did not show a statistically significant difference, we noted a peculiar finding in that the group that received the highest dose of $60 \mathrm{mg}$ for the longest duration of 7 days (group 60-7) had relatively low serum levels. A modified Tarlov score of 5 was achieved with a wide range of serum concentrations from 1.55 to $19.31 \mathrm{ng} / \mathrm{mL}$ (Figure 3, B) with no specific correlation between the modified Tarlov score and the serum level. This finding demonstrates that there is no cutoff value for the serum level or a particular dosing regimen that confers spinal cord protection, thus, leaving the door open for the possibility of a further reduction in the dose and duration of treatment.

von Euler and colleagues ${ }^{32}$ reported that memantine is not protective against spinal cord injuries in a rat model. Two years later, Ehrlich and colleagues ${ }^{19}$ showed that intravenous and intraarterial memantine is protective against spinal cord ischemia after aortic clamping in a rabbit model. After a careful search of the currently available literature, we did not find any further studies on memantine for spinal cord protection beyond rabbits, despite its clinically favorable side effect profile. Since Ehrlich and colleagues ${ }^{19}$ first showed its effectiveness in late 1990s, this topic remained dormant for more than a decade. We demonstrated that oral pretreatment with memantine is effective for the prevention of paraplegia in a rabbit model. Our treatment model is important because memantine is available only in oral form in Japan and as little as 3 days of oral treatment before surgery is effective for the prevention of spinal cord injury; therefore, its easy clinical application provides huge potential.

Other NMDA receptor antagonists that have been studied in animal models and have shown effectiveness for spinal protection include MK-801 and CGS19755. ${ }^{33,34}$ However, they have clinically intolerable side effects. After ischemic insult, glutamate and aspartate not only activate NMDA receptors but also activate $\alpha$-amino-3-hydroxy-5-methyl4-isoxazole proprionate (AMPA)-kainate receptor subtypes. ${ }^{35}$ AMPA-kainate receptor antagonists have also shown protection against spinal cord ischemia in animal models. ${ }^{36}$ However, these drugs are not yet in clinical use. Unlike AMPA-kainate receptor antagonists and other NMDA receptor antagonists, the safety profile of memantine is already proven and it is in clinical use for the treatment of Alzheimer dementia, favoring its choice over others.

MEPs have been used routinely for the detection of spinal cord ischemia during aortic surgery. In our laboratory, we have shown that in rabbits who have received memantine pretreatment, MEPs tend to persist longer after the aortic clamp is applied and reappear more frequently, although the MEP reappearance rate did not reach a level of statistical significance compared with the control group $(P=.073)$. Moreover, the amplitude loss by the end of surgery compared with the baseline value was significantly higher in the control group compared with the treatment groups. When the MEP reappeared in the control group, there was no significant difference in the time to reappearance compared with the memantine groups. This is because the MEP reappeared in only 2 rabbits in the control group. 
The memantine groups showed persistence of MEP for a longer period with a gradual decrease in amplitude until it finally became flat after aortic clamping; in the control group the MEP flattened abruptly immediately after or within a few minutes of aortic clamping (Figure 5).

The modified Tarlov score was significantly higher in the treatment groups compared with the control group at all observation times. The modified Tarlov score at 24,48 , and 72 hours was the same as that at 6 hours for all 5 groups, and no cases of delayed onset paraplegia were seen. Clinical evaluation closely correlated with the results of histopathology. Histopathologic grading was done by dividing the entire gray matter, excluding the posteriormost part containing sensory neurons, into 4 segments. By doing so, we were able to take even subtle changes in ischemia into consideration. Our findings open the possibility for another potential strategy in the armamentarium of TAAA repair; however, translation of these findings to large animal models or to clinical application needs to be further explored.

\section{CONCLUSIONS}

Memantine oral treatment is effective for the prevention of spinal cord injury during infrarenal aortic clamping in a rabbit model. Once daily oral pretreatment with memantine for as little as 3 days before surgery was shown to have spinal protection. As we move toward the path of excellency in aortic surgery, memantine can play its role as an additional strategy for the prevention of spinal cord injury.

\section{References}

1. Coselli JS, Conklin LD, LeMaire SA. Thoracoabdominal aortic aneurysm repair: review and update of current strategies. Ann Thorac Surg. 2002;74:S1881-4.

2. Crawford ES, Crawford JL, Safi HJ, Coselli JS, Hess KR, Brooks B, et al. Thoracoabdominal aortic aneurysms: preoperative and intraoperative factors determining immediate and long term results of operations in 605 patients. $J$ Vasc Surg. 1986;3:389-404.

3. Svensson LG, Crawford ES, Hess KR, Coselli JS, Safi HJ. Experience with 1509 patients undergoing thoracoabdominal aortic operations. J Vasc Surg. 1993;17: 357-70.

4. Cox GS, O'Hara PJ, Hertzer NR, Piedmonte MR, Krajewski LP, Beven EG. Thoracoabdominal aneurysm repair: a representative experience. J Vasc Surg. 1992; 15:780-8.

5. LeMaire SA, Rice DC, Schmittling ZC, Coselli JS. Emergency surgery for thoracoabdominal aortic aneurysms with acute presentation. J Vasc Surg. 2002;35:1171-8.

6. Livesay JJ, Cooley DA, Ventemiglia RA, Montero CG, Warrin RK, Brown DM, et al. Surgical experience in descending thoracic aneurysmectomy with and without adjuncts to avoid ischemia. Ann Thorac Surg. 1985;39:37-46.

7. Griepp RB, Ergin MA, Galla JD, Lansman S, Khan N, Quintana C, et al. Looking for the artery of Adamkiewicz: a quest to minimize paraplegia after operations for aneurysms of the descending thoracic and thoracoabdominal aorta. J Thorac Cardiovasc Surg. 1996;112:1202-15.

8. Etz CD, Halstead JC, Spielvogel D, Shahani R, Lazala R, Homann TM, et al. Thoracic and thoracoabdominal aneurysm repair: Is reimplantation of spinal cord arteries a waste of time? Ann Thorac Surg. 2006;82:1670-8.

9. Bekkers JA, te Riele RJLM, Takkenberg JJM, Raap GB, Hofland J, RoosHesselink JW, et al. Thoracic aortic surgery: An overview of 40 years clinical practice. J Thorac Cardiovasc Surg. 2014;147:332-43.

10. Acher C, Wynn M. Paraplegia after thoracoabdominal aortic surgery: not just assisted circulation, hypothermic arrest, clamp and sew, or TEVAR. Ann Cardiothorac Surg. 2012;1:365-72.
11. Griepp RB, Luozzo GD. Hypothermia for aortic surgery. J Thorac Cardiovasc Surg. 2013;145:S56-8.

12. Coselli JS, LeMaire SA, Koksoy C, Schmittling ZC, Curling PE. Cerebrospinal fluid drainage reduces paraplegia after thoracoabdominal aortic aneurysm repair: results of a randomized clinical trial. J Vasc Surg. 2002;35:631-9.

13. Coselli JS, LeMaire SA. Left heart bypass reduces paraplegia rates after thoracoabdominal aortic aneurysm repair. Ann Thorac Surg. 1999;67:1931-4.

14. Qayumi AK, Janusz MT, Dorovini-Zis K, Lyster DM, Jamieson WR, Poostizadeh A, et al. Additive effect of allopurinol and deferoxamine in the prevention of spinal cord injury caused by aortic crossclamping. J Thorac Cardiovasc Surg. 1994;107:1203-9.

15. Stys PK, Lipton SA. White matter NMDA receptors: an unexpected new therapeutic target? Trends Pharmacol Sci. 2007;28:561-6.

16. Chatterton JE, Awobuluyi M, Premkumar LS, Takahashi H, Talantova M, Shin Y, et al. Excitatory glycine receptors containing the NR3 family of NMDA receptor subunits. Nature. 2002;415:793-8.

17. Das S, Sasaki YF, Rothe T, Premkumar LS, Takasu M, Crandall JE, et al. Increased NMDA current and spine density in mice lacking NMDA receptor subunit NR3A. Nature. 1998;393:377-81.

18. Micu I, Ridsdale A, Zhang L, Woulfe J, McClintock J, Brantner CA, et al. Realtime measurement of free $\mathrm{Ca}^{2+}$ changes in CNS myelin by two-photon microscopy. Nat Med. 2007;13:874-9.

19. Ehrlich M, Knolle E, Ciovica R, Bock P, Turkof E, Grabenwoger M, et al. Memantine for prevention of spinal cord injury in a rabbit model. J Thorac Cardiovasc Surg. 1999;117:285-91.

20. Kawaharada N, Morishita K, Hyodoh K, Fujisawa Y, Fukuda J, Hachiro Y, et al. Magnetic resonance angiographic localization of the artery of Adamkiewicz for spinal cord blood supply. Ann Thorac Surg. 2004;78:846-52.

21. Nijenhuis RJ, Jacobs MJ, Schurink GW, Kessels AGH, van Engelshoven JMA, Backes WH. Magnetic resonance angiography and neuromonitoring to assess spinal cord blood supply in thoracic and thoracoabdominal aortic surgery. $J$ Vasc Surg. 2007;45:71-8.

22. Cull-Candy S, Brickley S, Farrant M. NMDA receptor subunits: diversity, development and disease. Curr Opin Neurobiol. 2001;11:327-35.

23. Lipton SA. Paradigm shift in neuroprotection by NMDA receptor blockade: memantine and beyond. Nat Rev Drug Discov. 2006;5:160-70.

24. Chen HSV, Lipton SA. Mechanism of memantine block of NMDA-activated channels in rat retinal ganglion cells: uncompetitive antagonism. J Physiol. 1997;499:27-46.

25. Chen HSV, Pellegrini JW, Aggarwal SK, Lei SZ, Warach S, Jensen FE, et al. Open-channel block of NMDA responses by memantine: therapeutic advantage against NMDA receptor-mediated neurotoxicity. J Neurosci. 1992;12:4427-36.

26. Lipton SA. Turning down, but not off. Nature. 2004;428:473.

27. Chen HSV, Lipton SA. The chemical biology of clinically tolerated NMDA receptor antagonists. J Neurochem. 2006;97:1611-26.

28. European Medicines Agency (EMEA). EPARs for authorized medicinal products for human use: Axura. European Public Assessment Report [online]. http://www. ema.europa.eu/docs/en_GB/document_library/EPAR_-_Product_Information/ human/000378/WC500029678.pdf. Accessed October 26, 2013.

29. Kornhuber J, Kennepohl EM, Bleich S, Wiltfang J, Kraus T, Reulbach U, et al. Memantine pharmacotherapy: a naturalistic study using a population pharmacokinetic approach. Clin Pharmacokinet. 2007;46:599-612.

30. Gomolin IH, Smith C, Jeitner TM. Once-daily memantine: pharmacokinetic and clinical considerations. J Am Geriatr Soc. 2010;58:1812-3.

31. Periclou A, Ventura D, Rao N, Abramowitz W. Pharmacokinetic study of memantine in healthy and renally impaired subjects. Clin Pharmacol Ther. 2006;79:134-43.

32. von Euler M, Li-Li M, Whittemore S, Seiger A, Sundstrom E. No protective effect of the NMDA antagonist memantine in experimental spinal cord injuries. $J$ Neurotrauma. 1997; 14:53-61.

33. Tobinaga S. Spinal cord protection: effect of N-methyl-D-aspartate receptor antagonist MK-801 for spinal cord ischemia in a rabbit model. Kurume Med J. 2000;47:45-53.

34. Cho Y, Ueda T, Mori A, Shimizu H, Yozu R. Neuroprotective effects of Nmethyl-D-aspartate receptor antagonist on aspartate induced neurotoxicity in the spinal cord in vivo. Jpn J Thorac Cardiovasc Surg. 2003;51:500-5.

35. Reece TB, Kern JA, Tribble CG, Cassada DC. The role of pharmacology in spinal cord protection during thoracic aortic reconstruction. Semin Thorac Cardiovasc Surg. 2003; 15:365-77.

36. Kanellopoulos GK, Xu XM, Hsu CY, Lu X, Sundt TM, Kouchoukos NT. White matter injury in spinal cord ischemia protection by AMPA/kainite glutamate receptor antagonism. Stroke. 2000;31:1945-52. 